\title{
Actinic keratosis prevention - A double-blind, half-face interventional study with a topical treatment
}

\author{
Elisabetta Sorbellini ${ }^{1}$, Barbara Marzani ${ }^{2}$, Daniela Pinto ${ }^{2}$, Fabio Rinaldi*1 \\ ${ }^{1}$ International Hair Research Foundation, Milan, Italy \\ ${ }^{2}$ Giuliani S.p.A. R\&D, Milan, Italy
}

Received: September 19, 2018

Accepted: November 18, 2018

Online Published: November 29, 2018

DOI: $10.5430 /$ jst.v9n1p1

URL: https://doi.org/10.5430/jst.v9n1p1

\begin{abstract}
Actinic keratosis (AK) is a chronic and recurrent disease and in this double-blind, half-face, placebo controlled study we attempted to examine the efficacy of a topical treatment containing 2,4,6-octatrienoic acid and anthraquinone knipholone for the prevention of new AK lesion formations. New lesion onset was detected with methyl-5-aminolevulinic acid and Wood's lamp after 6 months of treatment (T1) and 12 months after treatment end (T2). Absence of new lesion at T1, was $86.11 \%$ in active treatment side while $77.78 \%$ in placebo side. At T2 the percentage was higher in skin treated with active product (83.33\%) compared to placebo $(63.89 \%)$. Taking into consideration the number of new lesions during the study period, at $\mathrm{T} 1$ the new AK lesions were not statistically significantly influenced by the treatments, while at $\mathrm{T} 2$, AK lesions were detected in $30.55 \%$ of placebo-treated area while in the contralateral part the lesions were $13.89 \%$. The reduction induced by active treatment was statistically significant. The product containing 2,4,6-octatrienoic acid and anthraquinone knipholone is effective in reducing new AK lesion formation in subjects with a history of AKs.
\end{abstract}

Key Words: Actinic keratosis prevention, Actinic keratosis lesion onset, 2,4,6-octatrienoic acid, Anthraquinone knipholone

\section{INTRODUCTION}

Actinic keratosis (AK) is the most common diagnosed in the outpatient setting ${ }^{[1]}$ and the most common in situ cancerous skin lesion ${ }^{[2]}$ characterized by intraepithelial atypical proliferations of keratinocytes. ${ }^{[3]}$

Clinically, the lesions are presented as erythematous or fleshcolored, multiple, palpable macules, papule or plaques with a size from few millimeters to $>2 \mathrm{~cm} .{ }^{[4,5]}$ Telangiectasia and verrucous keratotic lesions could constitute other less reported clinical presentations. ${ }^{[4]}$ Mainly, AK lesions are asymptomatic, but some subjects report discomfort, such as burning sensation or itch. ${ }^{[6]}$

AK lesions can be classified, based on their appearances as atrophic, hypertrophic, pigmented, proliferative, lichenoid, acantholytic or Bowenoid. ${ }^{[7]}$ One of the major concern about this pathology is that any single AK lesion can evolve in invasive squamous cell carcinoma (SCC) and it is not possible to foresee the specific lesion progression. The situation is further complicated by spontaneous remission or stabilization. From an epidemiological point of view, data underline AK prevalence in fair-skinned subjects and in high-level sun exposure body areas. Even if probably underestimated, the incidence of AK is reported to be $16 \%-25 \%$ in USA, while $>20 \%$ in Europe. ${ }^{[8]}$

Studies of AK prevalence in Europe are limited, currently few data ara available on Spain, Germany, Netherlands. Only

*Correspondence: Fabio Rinaldi; Email: fabio.rinaldi@ studiorinaldi.com; Address: International Hair Research Foundation, Milan, Italy. 
two studies are available on Italian population where the prevalence rates vary greatly. The first one reported an AK prevalence of $1.4 \%$ with a higher incidence in Sicily and Sardinia; ${ }^{[9]}$ while the second one, hospital-based, reported a prevalence of $27.4 \%$ in dermatology outpatients. ${ }^{[10]}$

Since skin area affected by AK is the chronically sun-exposed area, chronic long-term solar radiation exposure represents the major AK risk factor. ${ }^{[11]}$ Other reported risk factors are specific phenotypic characteristics such as Fitzpatrick skin types I-III, photodamages (i.e. facial wrinkles), age and the number of hours spent in the sun. ${ }^{[12-14]}$ The last factor has also a strong impact on public health for outdoor workers due to their great occupational UV exposure. As a consequence, some Countries are working on to find and adopt strategies for decrease the potential incidence of this occupational disease.

Cumulative UV radiation induces DNA damage in keratinocyte creating genetically unstable cells, inactivating functional repair genes, such as p53, and inducing oxidative stress through the reactive oxygen species (ROS) production. $\mathrm{UV}$-damages not only can give rise to $\mathrm{AK}$, but represent also the common risk factor in progression of AK to SCC. ${ }^{[15]}$ Although this risk is considered relatively low and uncertain, the range is up to $0.53 \%$ in subjects with a history of nonmelanoma skin cancer, while the rate of lesion regression after one year is $15 \%-63 \%$ and the recurrence rate of lesions between $15 \%-53 \% .^{[16]}$

AK-derived photodamage can be extended from the lesional area to surrounded zone affected by subclinical alterations. ${ }^{[17]}$ The concept of "field cancerization" describes the area of molecular alterations observed in a chronical photodamage skin with several foci of non-melanocytic cutaneous neoplasm. ${ }^{[18]}$ All stages of AK progression can be present: from UV-damage keratinocytes, subclinical lesions (non-visible, non-palpable), early or late clinical lesions, and eventually SCCs. ${ }^{[18]}$ After the surgery for the primary AK lesion, the imperative clinical action is addressed to treat the entire field cancerization in order to reduce the lesion recurrences and prevent new lesion development. ${ }^{[18]}$ Many effective field-directed therapeutic options are available but the side effects, such as inflammation risk, scarring, dyschromia can potentially decrease patient treatment adherence.

As a consequence, there is a growing need for novel preventive strategies. The aim of this clinical study was to evaluate the efficacy and tolerability of a topical cosmetic treatment containing 2,4,6-octatrienoic acid and anthraquinone knipholone in the prevention of new AK lesion onset. Lesions were monitored by means of fluorescence diagnosis by coupling topical application of methyl ester of aminole- vulinic acid (MAL) to Wood's UV lamp with the aim to detect occult areas of abnormal skin. ${ }^{[3,19,20]}$ Previous preclinical studies reported the capacity of 2,4,6-octatrienoic acid to counteract photo-senescence in human fibroblast, increasing the biological antioxidant potential and the expression and activity of antioxidant enzyme catalase.

Moreover, in UV-irradiated normal human keratinocytes 2,4,6-octatrienoic acid showed a protective effect against UVA and UVB-induced damage and induction of DNA repair mechanisms. ${ }^{[21]}$ Anthraquinone knipholone from Bulbine frutescens extract is also included in the topical formulation as a selective inhibitor of leukotriene metabolism activated by UV damage. ${ }^{[22]}$

\section{MATERIALS AND METHODS}

The study has been conducted according to the principles of the Declaration of Helsinki and was performed in Milan on subjects residing in Lombardy region, Italy.

\subsection{Study population}

Eligibility criteria for study participation included: male and females 50 to 75 years of age with Fitzpatrick skin types I-III, skin photodamage grade $>3^{[23]}$ with at least 1 treated $\mathrm{AK}$ lesion in the past in sun-exposed area (scalp, face, decolletè) but the absence of AK lesions at the study inclusion.

Subjects were excluded from the study if within the six months before they received treatment interfering with the evaluations: facial chemical peel, or any other resurfacing procedure, botulinum toxin, facial fillers, immunosuppressive or immunomodulation agents, oral retinoids. Subjects were instructed to self-apply 1/day the 2 products on the half face, not to use any facial products nor procedures during the study.

\subsection{Study design}

In this double-blind placebo controlled trial, 36 eligible subjects applied the active product (2,4,6-octatrienoic acid, anthraquinone knipholone and excipients) to one-half of their face and placebo (excipients) to the opposite side, once daily for six months.

Subjects were asked to continue their normal life style during the study including the sun protection habits, and in case of sun, exposition to report any sun burn or erythema event. Moreover, during the study, a commercial sunscreen (Lichtena ${ }^{R}$ Dermosolari SPF 50+) was provided to all subjects.

Investigator assessments of new pre-cancerous lesions and tolerance were conducted at Baseline (T0), after 6 months of treatment (T1) and 12 months after treatment end (follow up, T2). Digital photographs of the left and right sides, der- 
matoscopic evaluation of the whole face were also taken at all visits.

All subjects underwent diagnosis with photodynamic technic with methyl-5-aminolevulinic acid (MAL) and Wood's lamp. MAL 5\% was topically applied in occlusion condition for 30 minutes (modified by Cubeddu et al., 1999). ${ }^{[19]}$ Then, the use of Wood's ultraviolet lamp permits the detection of cutaneous lesions as pink fluorescence in the presence of activated protoporphyrin IX from MAL. Prior treatment, the patient skin photodamage and absence of pre-cancerous lesions were assessed by the examining physicians. Each side was assessed separately.

\subsection{Study endpoints}

\subsubsection{Efficacy}

Investigator evaluations for the presence and new formation of pre-cancerous lesion on the left and right sides were graded separately. The pre-cancerous lesions were graded using a noninvasive fluorescence diagnosis by means of MAL $5 \%$ and Wood's lamp. ${ }^{[19]}$

\subsubsection{Safety}

Tolerance was assessed by investigators at $\mathrm{T} 1$ and $\mathrm{T} 2$ by objective irritation parameters (including erythema, edema, and scaling) on a four-point scale where $0=$ none, $1=$ mild, $2=$ moderate, and $3=$ severe; and the reporting of adverse events.

\subsubsection{Statistical analysis}

All values were expressed as mean \pm standard error of mean (SEM). Results were checked for normal distribution using Shapiro-Wilk test before further analyses. Statistical differences between groups were carried out by Welch's $t$-test, using GraphPad Prism version 7.00 for Windows (GraphPad Software, La Jolla California USA, www.graphpad.com). $p$-values equal to or less than .05 were considered significant.

\section{RESUltS}

36 subjects were enrolled in the study, 14 men and 22 women (38.9\% and $61.1 \%$, respectively). The mean age was $61 \pm 6$ years (see Table 1).

Table 1. Age and gender distribution in patients

\begin{tabular}{lll}
\hline Gender & $\mathbf{N}$ & Mean age (SEM) \\
\hline Female & 22 & $61.64(6.40)$ \\
Male & 14 & $61.57(6.06)$ \\
\hline
\end{tabular}

All subjects concluded the study and no side effect was reported by the patient or by physician evaluation by means of objective irritation parameters.
After 6 months of treatment (T1), the clinical benefit, represented by absence of new lesion, in area treated with active product was $86.11 \%$ (90.91\% women and $78.57 \%$ men) while the placebo side, the clearance was $77.78 \%(77.27 \%$ of women and $71.43 \%$ of men). At follow-up, 12 months after end of treatment (T2), the frequency of sustained cleared lesions was higher in skin area treated with active product ( $83.33 \%$ of subjects, $90.91 \%$ women and $71.43 \%$ men) compared to placebo effect ( $63.89 \%$ of subject, $68.18 \%$ of women and $57.14 \%$ of men) (see Table 2).

Table 2. Clinical benefit during the study period

\begin{tabular}{lll}
\hline & $\begin{array}{l}\text { Clearance rate } \\
\%\end{array}$ & $\begin{array}{l}\text { Sustained clearance rate } \\
\%\end{array}$ \\
\cline { 2 - 3 } & $\mathrm{T} 1$ & $\mathrm{~T} 2$ \\
\hline Active side & & \\
Men & 78.57 & 71.43 \\
Women & 90.91 & 90.91 \\
Total & 86.11 & 83.33 \\
Placebo side & & \\
Men & 71.43 & 57.14 \\
Women & 77.27 & 68.18 \\
Total & 77.78 & 63.89 \\
\hline
\end{tabular}

In particular, as regard the appearance of new lesions, after 6 months of treatment (T1), new AK lesions were present in $25 \%$ of area treated with placebo ( 4 men and 5 women) while, $13.89 \%$ in the face zone treated with active product ( 3 men and 2 women). At T1 the mean ( \pm SEM) number of new AK lesion was not statistically significantly influenced by the treatments. At T2, after 12 months from treatment end, AK lesions were detected in $30.55 \%$ of placebo-treated side (in 5 men and 6 women) while $13.89 \%$ in the contralateral treated side (in 3 men and 2 women) (see Table 3 ).

Table 3. New lesion in the face area treated with active product and contralateral part treated with placebo

\begin{tabular}{lll}
\hline & \multicolumn{2}{l}{ Subjects with new lesion (number) } \\
\cline { 2 - 3 } & T1 & T2 \\
\hline Active side & & 3 \\
Men & 3 & 2 \\
Women & 2 & 13.89 \\
Total (\%) & 13.89 & \\
Placebo side & & 5 \\
Men & 4 & 6 \\
Women & 5 & 30.55 \\
Total (\%) & 25 & \\
\hline
\end{tabular}


The AK mean ( \pm SEM) number measured during the followup in placebo area shown the disease progression, while active treatment induced a statistically significant reduction in the new AK formation $(p<.05$, see Figure 1$)$.

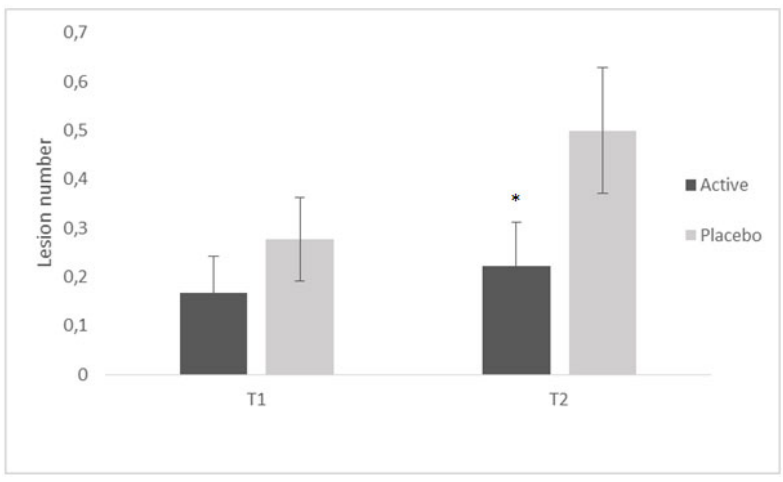

Figure 1. Mean $\pm \mathrm{SEM}$ of AK lesion detected at T1 (6 months of treatment) and T2 (12 months after the treatment end) in 36 subjects treated half face with placebo and contralateral half face with active product. $* p<.05$ active treatment vs. placebo treatment.

\section{Discussion}

$\mathrm{AK}$ is extremely frequent in dermatological clinical practice. AK treatment needs to reduce the risks of progression, but complete lesion clearance is rarely achieved in real-life practice. ${ }^{[24]}$ Because of its chronicity, AK presents a high recurrence rate despite the previous treatment received. ${ }^{[8]}$ Recurrence of lesions was reported in $65 \%$ of subjects 1 year after 5-Fluorouracil (5-FU) treatment; ${ }^{[25]}$ a range from 17.4 to $39 \%$ of recurrence 1 year after Imiquimod treatment; $[25,26]$ while $54 \%-56 \%$ in Ingenol mebutate treated patients, after 1 year. ${ }^{[27]}$

In any case, field-directed treatments are essential to address subclinical damage and reduce $\mathrm{AK}$ recurrence rates and potentially reduce the risk of SCC development. ${ }^{[28-31]}$

The AK development is due to damages from chronic sun exposure and because of its potential progression to invasive squamous cell carcinoma, treatment and preventive measures are required.

Some efforts have been done to prevent AK lesions and progression, the use of sunscreen is one of this measure. In a randomized controlled trial, it was evaluated the regular use of sunscreen and the new keratosis appearances in Australian subjects during summer. The data showed that regular use of sunscreen prevents the formation of new keratosis and accelerate the remission of present lesions. ${ }^{[32]}$ Another study confirmed that regular application of sunscreen delays the new lesion formation. ${ }^{[33]}$

However, sunscreen seems not able to reduce the BCCs 4 incidence, ${ }^{[34]}$ so many other attempts are made for an alternative form of chemoprevention. Sunscreen use and patient education are the first line prevention strategy, but not the only. An interesting study was conducted by Elments and colleague $^{[35]}$ in which the drug Celecoxib, an inhibitor of cyclooxygenase, ${ }^{[2]}$ was effective in SCC prevention, but not in the modulation of new AK formation.

The Italian studies ${ }^{[9,10]}$ were preparatory for our investigation and in particular to subject selection: we decided to limit our patient inclusion to a single Italian region, Lombardy, in order to have a more homogeneous population in terms of habits, general sun irradiation and lifestyles.

Due to the formulation characteristic, cosmetics can be used in the management of AK lesions, i.e. the unappealing aspect of the AK lesions can be improved by cosmetic emollients with an effect on patient comfort by means of skin dryness and roughness reduction. ${ }^{[36]}$

The cosmetic for its intrinsic nature is more easy to use: not particular recommendations or indications are needed. Sunscreen use is recommended by different Guidelines for the AK prevention and management, but often the real consumer use condition makes the photoprotection inefficacy due to: the low amount product applied (with a significative reduction in sun protection, up to $25 \%$ of labeled SPF), ${ }^{[37]}$ and low compliance to this type of cosmetics.

Previous in vivo assays demonstrated the capacity of 2,4,6octatrienoic acid to protect and counteract UV-induced DNA damage. Pre- or post-treatment with 2,4,6-octatrienoic acid accelerate DNA repair decreasing cyclobutane-pyrimidine dimers, 7,8-dihydro-8-oxoguanine, and levels of phosphorylated histone H2A.X, associated with the amount of DNA double-strand breaks by UV radiation. ${ }^{[38]}$

The performed study shows that the use of a topical formulation containing 2,4,6-octatrienoic acid and anthraquinone knipholone for 12 months could help the reduction of new AK lesions formation, decreasing also skin photo-aging in treated subjects.

\section{Conclusion}

As a chronic disease, AK treatment need a long-term disease control and prevention. It is of primary importance to find new products to delay the recurrence and new lesion formation in the skin sun damaged areas.

In this double-blind trial, the product containing 2,4,6octatrienoic acid and anthraquinone knipholone is effective in reducing new AK lesion formation in subjects with a history of AKs in "real life condition". 
Further studies with longer follow up are necessary to confirm treatment prolonged efficacy.

Therefore, based on our experience, secondary prevention by a cosmetic product should be extended in dermatological practice to minimized the photo-induced skin damage and to prevent recurrence in patients with a history of AK.

Patient regular monitoring, with at least a yearly consultation, can be performed by means of fluorescent detection by
Wood's lamp and MAL (5\%), an essential noninvasive diagnostic tool. This method is extremely helpful in permitting the detection of otherwise occult areas of abnormal skin with the advantage of in vivo tissue examination reducing the biopsy need and it is well accepted by patients.

\section{CONFlicts of InTEREST Disclosure}

R.F. serves as a consultant for Giuliani S.p.A. P.D. and M.B. are employed by Giuliani S.p.A.

\section{REFERENCES}

[1] Bickers DR, Lim HW, Margolis D, et al. American Academy of Dermatology Association; Society for Investigative Dermatology. The burden of skin diseases: 2004 a joint project of the American Academy of Dermatology Association and the Society for Investigative Dermatology. J Am Acad Dermatol. 2006 Sep; 55(3): 490-500. https://doi.org/10.1016/j.jaad.2006.05.048

[2] Casari A, Chester J, Pellacani G. Actinic Keratosis and Non-Invasive Diagnostic Techniques: An Update. Biomedicines. 2018; 6(1): E8. https://doi.org/10.3390/biomedicines6010008

[3] Jetter N, Chandan N, Wang S, et al. Field Cancerization Therapies for Management of Actinic Keratosis: A Narrative Review. Am J Clin Dermatol. 2018 Mar; 26. https://https://doi.org/10.1 007/s40257-018-0348-7

[4] Siegel JA, Korgavkar K, Weinstock MA. Current perspective on actinic keratosis: A review. Br J Dermatol. 2017 Aug; 177(2): 350-358. https://doi.org/10.1111/bjd.14852

[5] Salasche SJ. Epidemiology of actinic keratoses and squamous cell carcinoma. J Am Acad Dermatol. 2000 Jan; 42(1): 4-7. https: //doi.org/10.1067/mjd.2000.103342

[6] Rosen T, Lebwohl MG. Prevalence and awareness of actinic keratosis: barriers and opportunities. J Am Acad Dermatol. 2013 Jan; 68(1 Suppl 1): S2-9. https://doi.org/10.1016/j.jaad.2012.09 .052

[7] Peris K, Calzavara-Pinton PG, Neri L, et al. Italian expert consensus for the management of actinic keratosis in immunocompetent patients. J Eur Acad Dermatol Venereol. 2016 Jul; 30(7): 1077-84. https://doi.org/10.1111/jdv.13648

[8] Dodds A, Chia A, Shumack S. Actinic keratosis: rationale and management. Dermatol Ther (Heidelb). 2014 Jun; 4(1): 11-31. https://doi.org/10.1007/s13555-014-0049-y

[9] Naldi L, Chatenoud L, Piccitto R, et al. Prevalence of Actinic Keratoses Italian Study (PraKtis) Group. Prevalence of actinic keratoses and associated factors in a representative sample of the Italian adult population: Results from the Prevalence of Actinic Keratoses Italian Study, 2003-2004. Arch Dermatol. 2006 Jun; 142(6): 722-6. https://doi.org/10.1001/archderm.142.6.722

[10] Fargnoli MC, Altomare G, Benati E, et al. Prevalence and risk factors of actinic keratosis in patients attending Italian dermatology clinics. Eur J Dermatol. 2017 Dec; 27(6): 599-608.

[11] Berman B, Cockerell CJ. Pathobiology of actinic keratosis: ultraviolet-dependent keratinocyte proliferation. J Am Acad Dermatol. 2013 Jan; 68(1 Suppl 1): S10-9. https://doi.org/10.1 016/j.jaad. 2012.09.053

[12] Kennedy C, Bajdik CD, Willemze R, et al. Leiden Skin Cancer Study. The influence of painful sunburns and lifetime sun exposure on the risk of actinic keratoses, seborrheic warts, melanocytic nevi, atypical nevi, and skin cancer. J Invest Dermatol. 2003 Jun; 120(6): 1087-93. https://doi.org/10.1046/j.1523-1747.2003.12246.x

[13] Traianou A, Ulrich M, Apalla Z, et al. Risk factors for actinic keratosis in eight European centres: a case-control study. Br J Dermatol. 2012 Aug; 167(Suppl 2): 36-42. https://doi.org/10.1111/j. 1365-2133.2012.11085. $\mathrm{x}$

[14] Krutmann J, Berking C, Berneburg M, et al. New Strategies in the Prevention of Actinic Keratosis: A Critical Review. Skin Pharmacol Physiol. 2015; 28(6): 281-9. https://doi.org/10.1159/0004 37272

[15] Emmert S, Schön MP, Haenssle HA. Molecular biology of basal and squamous cell carcinomas. Adv Exp Med Biol. 2014; 810: 234-52. https://doi.org/10.1007/978-1-4939-0437-2_13

[16] Werner RN, Sammain A, Erdmann R, et al. The natural history of actinic keratosis: A systematic review. Br J Dermatol. 2013 Sep; 169(3): 502-18. https://doi.org/10.1111/bjd.12420

[17] Malvehy J. A new vision of actinic keratosis beyond visible clinical lesions. J Eur Acad Dermatol Venereol. 2015 Jan; 29(Suppl 1): 3-8. https://doi.org/10.1111/jdv. 12833

[18] Torezan LA, Festa-Neto C. Cutaneous field cancerization: Clinical, histopathological and therapeutic aspects. An Bras Dermatol. 2013 Sep-Oct; 88(5): 775-86. https ://doi .org/10.1590/abd1 $806-4841.20132300$

[19] Cubeddu R, Pifferi A, Taroni P, et al. Fluorescence Lifetime Imaging: An Application to the Detection of Skin Tumors IEEE. Journal of Selected Topics in Quantum Electronics. 1999 Jul/Aug; 5(4): 923-29.

[20] Sanmartin O, Guillen C. Images in clinical medicine. Fluorescence diagnosis of subclinical actinic keratoses. N Engl J Med. 2008 May; 358(19): e21. https://doi.org/10.1056/NEJMicm071130

[21] Briganti S, Flori E, Bellei B, et al. Modulation of PPAR $\gamma$ provides new insights in a stress induced premature senescence model. PLoS One. 2014 Aug; 9(8): e104045. https://doi .org/10.1371/jo urnal. pone. 0104045

[22] Wube AA, Bucar F, Asres K, et al. A selective inhibitor of leukotriene metabolism. Phytomedicine. 2006 Jun; 13(6): 452-6. https ://doi. org $/ 10.1016 / j$. phymed .2005 .01 .012

[23] Glogau RG. Aesthetic and anatomic analysis of the aging skin. Semin Cutan Med Surg. 1996 Sep; 15(3): 134-8.

[24] Krawtchenko N, Roewert-Huber J, Ulrich M, et al. A randomised study of topical 5\% imiquimod vs. topical 5-fluorouracil vs. cryosurgery in immunocompetent patients with actinic keratoses: a comparison of clinical and histological outcomes including 1year follow-up. Br J Dermatol. 2007 Dec; 157(Suppl 2): 34-40. https://doi.org/10.1111/j.1365-2133.2007.08271.x 
[25] Lebwohl M, Dinehart S, Whiting D, et al. Imiquimod 5\% cream for the treatment of actinic keratosis: results from two phase III, randomized, double-blind, parallel group, vehicle-controlled trials. J Am Acad Dermatol. 2004 May; 50(5): 714-21. https: //doi.org/10.1016/j.jaad.2003.12.010

[26] Lebwohl M, Swanson N, Anderson LL, et al. Ingenol mebutate gel for actinic keratosis. N Engl J Med. 2012 Mar; 366(11): 1010-9. https ://doi .org/10.1056/NEJMoa1111170

[27] Ulrich M, Lange-Asschenfeldt S, Rowert-Huber J. Effects of ingenol mebutate $0.05 \%$ gel for the treatment of actinic field cancerization including subclinical actinic keratoses - assessment by reflectance confocal microscopy. Br J Dermatol. 2014; 171(Suppl 4): 1-76.

[28] Cantisani C, De Gado F, Ulrich M, et al. Actinic keratosis: Review of the literature and new patents. Recent Pat Inflamm Allergy Drug Discov. 2013 May; 7(2): 168-75. https://doi.org/10.2174/18 72213X11307020008

[29] Ulrich M, Alarcon I, Malvehy J, et al. In vivo reflectance confocal microscopy characterization of field-directed 5-fluorouracil $0.5 \% / \mathrm{sali}$ cylic acid 10\% in actinic keratosis. Dermatology. 2015; 230: 193-198. https://doi.org/10.1159/000370148

[30] Cantisani C, Paolino G, Corsetti P, et al. Evaluation of Ingenol mebutate efficacy for the treatment of actinic keratosis with Antera 3D camera. Eur Rev Med Pharmacol Sci. 2015; 19: 92-97.

[31] Thompson SC, Jolley D, Marks R. Reduction of solar keratoses by regular sunscreen use. N Engl J Med. 1993 Oct; 329(16): 1147-51. https://doi.org/10.1056/NEJM199310143291602

[32] Darlington S, Williams G, Neale R, et al. A randomized controlled trial to assess sunscreen application and beta carotene supplementa- tion in the prevention of solar keratoses. Arch Dermatol. 2003 Apr; 139(4): 451-5. https ://doi.org/10.1001/archderm.139.4.4 51

[33] Green A, Williams G, Neale R, et al. Daily sunscreen application and betacarotene supplementation in prevention of basal-cell and squamous-cell carcinomas of the skin: a randomised controlled trial. Lancet. 1999 Aug; 354(9180): 723-9. Erratum in: Lancet 1999 Sep 18; 354(9183): 1038. https://doi.org/10.1016/S0140-673 6 (98) 12168-2

[34] Elmets CA, Viner JL, Pentland AP, et al. Chemoprevention of nonmelanoma skin cancer with celecoxib: A randomized, double-blind, placebo-controlled trial. J Natl Cancer Inst. 2010 Dec; 102(24): 183544. https://doi.org/10.1093/jnci/djq442

[35] Dréno B, Amici JM, Basset-Seguin N, et al. Management of actinic keratosis: A practical report and treatment algorithm from AKTeam $^{\mathrm{TM}}$ expert clinicians. J Eur Acad Dermatol Venereol. 2014 Sep; 28(9): 1141-9. https : //doi .org/10.1111/jdv.12434

[36] Neale R, Williams G, Green A. Application patterns among participants randomized to daily sunscreen use in a skin cancer prevention trial. Arch Dermatol. 2002 Oct; 138(10): 1319-25.

[37] Dirschka T, Gupta G, Micali G, et al. Real-world approach to actinic keratosis management: Practical treatment algorithm for officebased dermatology. J Dermatolog Treat. 2017 Aug; 28(5): 431-442. https://doi.org/10.1080/09546634.2016.1254328

[38] Flori E, Mastrofrancesco A, Kovacs D, et al. The activation of $\operatorname{PPAR} \gamma$ by 2,4,6-Octatrienoic acid protects human keratinocytes from UVR-induced damages. Sci Rep. 2017 Aug; 7(1): 9241. https://doi .org/10.1038/s41598-017-09578-3 